\title{
Myoinositol causes myometrial contractions in isolated non-pregnant rat myometrium
}

\author{
Ebru Çelik Kavak ${ }^{1^{*}}$, Emine Kaçar ${ }^{2}$, Salih Burçin Kavak ${ }^{1}$, Özgür Bulmuş ${ }^{2}$, İhsan \\ Serhatlıoğlư ${ }^{2}$, Ahmet Tektemur ${ }^{2}$ \\ 'Firat University, School of Medicine, Department of Obstetrics and Gynecology, Elarig, Turkey \\ ${ }^{2}$ Firat University, School of Medicine, Department of Physiology, Elarig, Turkey
}

\begin{abstract}
We aimed to investigate myoinositol effect on contractility of rat uterus in vitro and its mechanism of action. In a standard organ bath spontaneous contractions were recorded. After the cessation of spontaneous contractions, $5 \mu \mathrm{M}, 50 \mu \mathrm{M}$ and 500 $\mu \mathrm{M}$ of myoinositol and $20 \mu \mathrm{M}$ folic acid were applied to each 7 strips and contractions were again enrolled. Same procedures were also repeated in calcium free solution. Real Time Polymerase Chain Reaction (RT-PCR) analysis of ion channels were done only for $50 \mu \mathrm{M}$ myoinositol which corresponds to the treatment dose. It is demonstrated that in all doses increase in frequency and amplitude of contractions were statistically significant. Any contraction was not observed in calcium free solution which demonstrated us that myoinositol uses extracellular calcium for contraction. It is also demonstrated that folic acid does not cause contraction in non pregnant rat uterine smooth muscle cells. Expression of Transient receptor potential cation channel, subfamily M, member 2 (TRPM2) and Transient receptor potential cation channel, subfamily V, member 1 (TRPV1) channels significantly decreased after application of myoinositol $(\mathrm{p}=0.01$, for both) whereas expression of Transient receptor potential cation channel, subfamily M, member 7 (TRPM7) and Calcium channel, voltage-dependent, $\mathrm{N}$ type, alpha 1B subunit (CACNA1B) channels did not change significantly when compared to control (for both). We demonstrated for the first time that myoinositol causes contraction in myometrium of nonpregnant rat uterus and it uses the extracellular calcium for contraction.
\end{abstract}

Key Words: myoinositol, rat uterus, contraction

\section{Introduction}

Polycystic ovary syndrome (PCOS) influences up to $20 \%$ of women in child bearing age (1). It represents a common cause of female infertility. In recent years, effect of inositol in PCOS is demonstrated by many studies (2).

Inositol was discovered in 1850 (3). Myoinositol is a form of inositol and is naturally present in many kinds of plants especially fruit and beans (4). Myoinositol can also be synthesized in the body from glucose-6-phosphate. It is a component of cell membrane and it is needed for the development and life of human cells in the culture (5).

It has been demonstrated that inositol, by itself or its derivatives, is important in cytoskeleton reaarrangement, morphogenesis, regulation of cell proliferation, control of intracellular calcium and maintainance of cell membrane potential $(6,7)$. It is present in high concentrations in reproductive organs of males and females $(8,9)$.

Contractility of uterus smooth muscle is mostly related to influx of calcium from the extracellular space however release of calcium from endoplasmic reticulum can also increase calcium levels and cause contraction. The endoplasmic reticulum calcium stores can be accessed upon stimulation by inositol. Phospholipase C can produce inositol -1,4,5 triphosphate that causes discharge of sequestrated calcium out of the endolasmic reticulum. Oxytocin is an important hormone and it also uses this phospholipase C pathway. Because of this effect, use of inositol during pregnancy is not recommended (10).

Increase in intracellular calcium occurs by the use of different calcium channels among which the superfamily of transient receptor potential (TRP) proteins are the newly discovered ones. TRP ion channels are classified into seven related families. They are widely distributed in many cell types and they work in many physiological processes. Majority of TRP channels are non-selective and they work together with other ion channels (11).

We herein aimed to determine myoinositol effect on non pregnant rat uterus muscle contraction, its mechanism of action and possible roles of four different channels on contraction. These are

\footnotetext{
${ }^{*}$ Corresponding Author: Ebru Çelik Kavak, MD, Assistant Professor, Firat University, School of Medicine, Department of Obstetrics and Gynecology, 23100, Elazig, Turkey, Phone: +90 42423335 55-2124, Fax: +90 42423791 38, E-mail: eckavak@gmail.com, drkavak@yahoo.com.tr
} 
Transient receptor potential cation channel, subfamily M, member 2 (TRPM2) and Transient receptor potential cation channel, subfamily $\mathrm{V}$, member 1 (TRPV1) channels which are located in intracellular compartments and responsible from the release of calcium and Transient receptor potential cation channel, subfamily $\mathrm{M}$, member 7 (TRPM7) and Calcium channel, voltagedependent, $\mathrm{N}$ type, alpha 1B subunit (CACNA1B) are present on cell membrane and responsible from influx of extracellular calcium (12-14).

To our knowledge despite its common use in infertile patients and its known effect on calcium metabolism, this is the first study demonstrating the effect of myoinositol on uterine contractility and investigating its mechanism of action.

\section{Materials and methods}

Animals - Drugs and Solutions: Permission for the study was given by local ethics committee and the experiments were carried out in the Laboratory for Animal Experimentation, Firat University, Elazig, Turkey. 28 female nonpregnant Spraque Dawley rats weighting between 200-250 g, aged 10-12 weeks were used in the study. Vaginal smears were done and animals showing regular cycles were selected on the day of diestrus. After decapitation, we took out the uterus and put in Krebs solution.

Agent used in the study was myoinositol (Inofolic Sachet, Italfarmaco, Milano, Italy). Since folic acid was also present in the preperation used in the experiment, we also examined its effect by using a seperate folic acid preperation (Folbiol, I.E.Ulagay, Turkey). They were dissolved in required amounts before application into the organ bath. The ingredients of Krebs-Henseit solution were obtained from Sigma (Disenhofen, Germany).

Measurement of Contractility: For the analysis of contractility, one longitudinal smooth muscle strip measuring $12 \times 2 \times 1 \mathrm{~mm}$ were prepared from each rat and 7 strips were used for each drug dose. One of the tips was attached to a metal hook and the other to an isometric force-displacement transducer. Myometrial strips were $(\mathrm{p}<0.05$, for all) suspended in a standard organ bath containing Krebs-Henseit solution. Experiments were performed at $37^{\circ} \mathrm{C}$ and solution was aerated with a mixture of $95 \% \mathrm{O}_{2}$ and $5 \% \mathrm{CO}_{2}$.

Experiment medium was washed in every 30 minutes. After an equilibration period under a tension of $1 \mathrm{~g}$, regular spontaneous contractions were recorded for 10 minutes. Physiologic power converter (FDT05, Commat Ltd, Ankara, Turkey) was used and results were enrolled by MP150 WS Windows programme. Contractions were followed and after the complete cessation of contractions 5 $\mu \mathrm{M}$ myoinositol was added into the organ bath and contractions were again recorded for 10 minutes. This procedure was repeated for $50 \mu \mathrm{M}$ and $500 \mu \mathrm{M}$ doses. The washing of the bath after each procedure prevented the formation of cumulative dose. To determine the mechanism of action, the effect of the drug is also studied in calcium free solution. At the end of the process, tissue fragments to which $50 \mu \mathrm{M}$ drug was applied, were taken for genetic analysis.

Contractile activities are quantified by calculating the amplitude, frequency and area under curve (AUC). Results of frequency are reported as number of contractions per 10 minute and data of amplitude are given as miligrams (mg).

Quantitative Real time PCR assays: RT-PCR analysis of ion channels were done only for $50 \mu \mathrm{M}$ dose of myoinositol which corresponds to the treatment dose.

A piece of myometrium measuring approximately $100 \mathrm{mg}$ were taken from the seven rat uteri, to whom $50 \mu \mathrm{M}$ dose of drug was planned to apply, for RT-PCR analysis just after removal from the body and put into RNA latter solution. Muscle tissues that were treated with $50 \mu \mathrm{M}$ dose of myoinositol were also taken into RNA latter solution after the procedure. Total RNA of uteri were isolated using TRIzol reagent (Invitrogen, Carlsbad, CA). Random primedcDNAs were generated by reverse transcription of total RNA samples with High Capacity RNA to cDNA Synthesis kit (P/N:4387406, Applied Biosystem, USA). The $20 \mu \mathrm{l}$ reactions were incubated in an Applied Biosystems 7500 Fast Thermo cycler in a 96-well platefor $30 \mathrm{~min}$. at $16^{\circ} \mathrm{C}, 30 \mathrm{~min}$. at $42^{\circ} \mathrm{C}$, 5 min. at $85^{\circ} \mathrm{C}$ and then held at $4^{\circ} \mathrm{C}$. Tag Man Assays ID numbers are shown in Table 1. RNA samples were normalized based on the TaqMan ${ }^{\circledR}$ Gene Expression Assays formouse glyceraldehyde-3-phosphate dehydrogenase (GAPDH) endogenous controls. RT-PCR was performed using a Standard TaqMan ${ }^{\circledR}$ PCR kit (P/N:4370074, AppliedBiosystem, USA) protocol on an Applied Biosystems 7500 Fast thermal Cycler. It was incubated in a 96 -well plate at $95^{\circ} \mathrm{C}$ for $10 \mathrm{~min}$, followed by 40 cycles of $95^{\circ} \mathrm{C}$ for $15 \mathrm{~s}$. and $60^{\circ} \mathrm{C}$ for $1 \mathrm{~min}$. All reactions were run in triplicate. The samples were quantified for all genes using the comparative $\mathrm{Ct}(\Delta \Delta \mathrm{Ct})$ method, as described in the Assays-on-Demand Users Manual 
(AppliedBiosystems). In Table 1 gene names and assay IDs are given:

Statistical Anaysis: The data are given as means \pm SD. All statistics were done by statistical programme SPSS for Windows (version 21.0.1, SPSS, Inc. Chicago, Illinois). Since the datas showed normal distribution, paired $t$ test was performed. $\mathrm{p}<0.05$ was recognized as statistically significant.

\section{Results}

We obtained spontaneous contractions in strips.

Results of isolated organ bath: In uterine strips from non pregnant rats, myoinositol caused significant increase in the contractile activity in all doses. Application of $5 \mu \mathrm{M}, 50 \mu \mathrm{M}$ and $500 \mu \mathrm{M}$ of

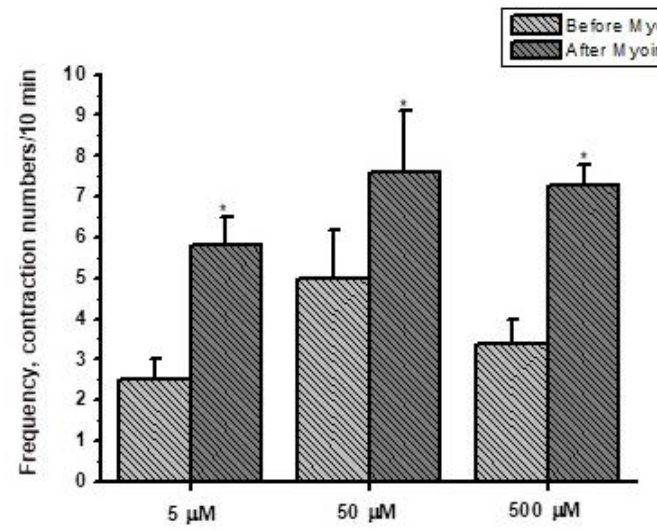

Fig. 1. Effect of different doses of myoinositol on frequency of uterus contraction. (n:7). Results are given as mean \pm S.D. Asteriks $\left(^{*}\right)$ means significant difference from its own control $(p<0.05)$.

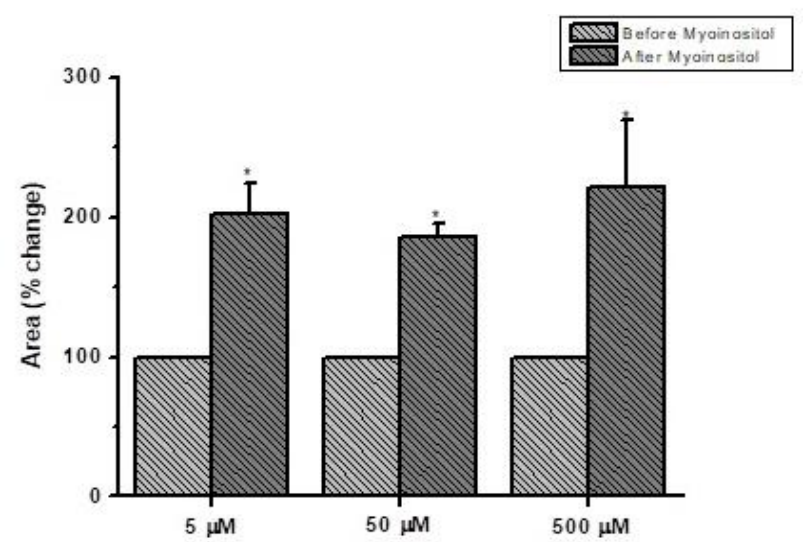

Fig. 3. Effects of different doses of myoinositol on area under curve (AUC) of uterus contraction. (n:7). Results are given as mean \pm S.D. Asteriks $\left(^{*}\right)$ means significant difference from its own control $(\mathrm{p}<0.05)$. myoinositol increased the frequency of contraction $128.9 \%, \quad 50,8 \%$ and $112.7 \%$ respectively (Figure 1). Increase in amplitude of contractions were as $13.8 \%, 10.3 \%$ and $23.4 \%$ respectively (Figure 2). All the results were statistically significant $(\mathrm{p}<0.05)$.

When the area under curve is calculated, it is observed that increase is statistically significant in all doses. Increase is $202.9 \%(\mathrm{p}<0.05)$ in $5 \mu \mathrm{M}$ dose; 186.1\% $(\mathrm{p}<0.05)$ in the $50 \mu \mathrm{M}$ dose and $222.8 \%(\mathrm{p}<0.05)$ in the $500 \mu \mathrm{M}$ dose (Figure 3).

Same procedures were also repeated in a calcium free solution and any contraction was not observed at any dose in this solution. These results showed that myoinositol most probably causes conractions by using the extracellular calcium.

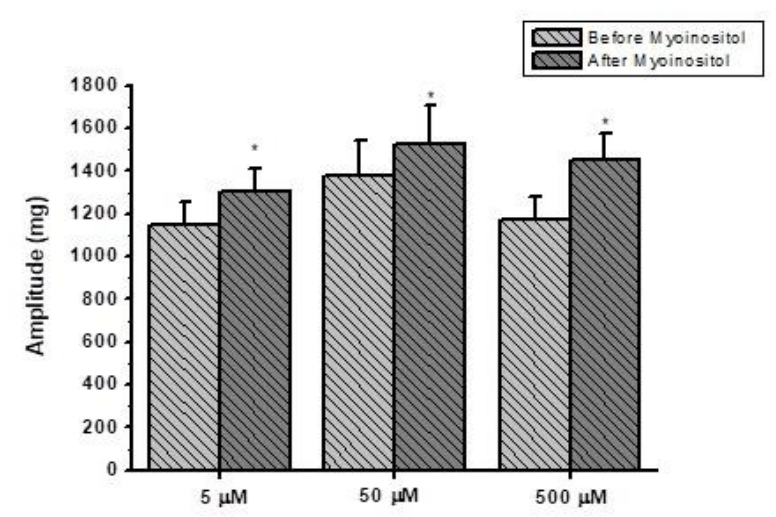

Fig. 2. Effects of different doses of myoinositol on amplitude of uterus contraction. (n:7). Results are given as mean \pm S.D. Asteriks $\left(^{*}\right)$ means significant difference from its own control $(\mathrm{p}<0.05)$.

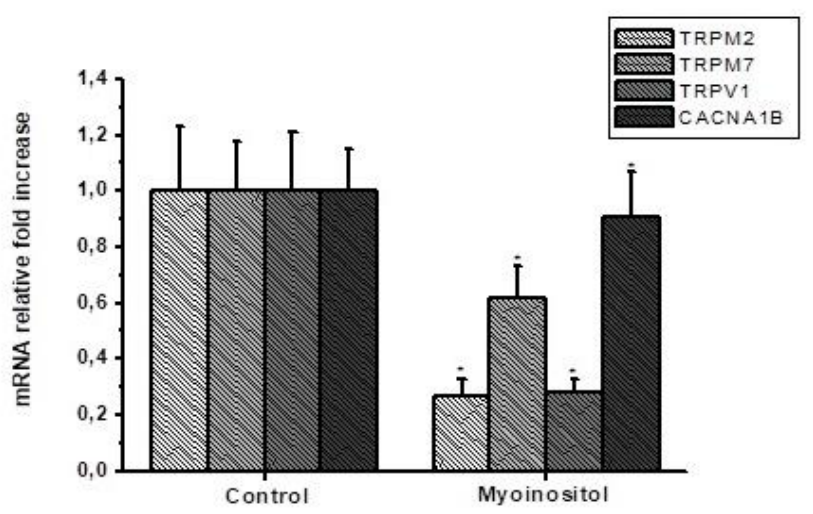

Fig. 4. Quantitative real time PCR analysis of TRPM2, TRPM7, TRPV1 and CACNA1B in uterus tissue of nonpregnant rat before and after the application of $50 \mu \mathrm{M}$ myoinositol. (n:7). The symbol asteriks $\left(^{*}\right)$ indicates significant difference $(p<0.05)$. 
Table 1. Assay identifiers (IDs) used for qRT-PCR.

\begin{tabular}{|c|c|c|}
\hline Gene Symbol & Gane Name & AssaysIDs \\
\hline TRPM2 & $\begin{array}{l}\text { Transiente receptor potential cationchannel, subfamily M, } \\
\text { member } 2\end{array}$ & Rn01429410_ml \\
\hline TRPM7 & $\begin{array}{l}\text { Transiente receptor potential cation channel, subfamily M, } \\
\text { member } 2\end{array}$ & Rn01328216_ml \\
\hline TRPV1 & $\begin{array}{l}\text { Transiente receptor potential cationchannel, subfamily } \mathrm{V} \text {, } \\
\text { member } 1\end{array}$ & Rn00583117_ml \\
\hline CACNA1B & $\begin{array}{c}\text { Calcium channel, voltage-dependent, } \mathrm{N} \text { type, alpha 1B } \\
\text { subunit }\end{array}$ & Rn01643813_ml \\
\hline Gapdh & Glycer aldehyde-3-phosphate dehydrogenase & Rn01775763_gl \\
\hline
\end{tabular}

Folic acid effect is also evaluated. $20 \mu \mathrm{M}$ folic acid, which corresponds to the dose used in the preperate, was applied and no contraction was observed. After the observation of this effect, oxitocin was also applied to the medium to show the viability of these strips. Contractions were observed in all strips after the application of oxytocin which confirmed that all the tissues were viable and folic acid does not cause contraction in uterine muscle.

Results of Quantitative Real time PCR Assays: TRPM2 and TRPV1 expression significantly decreased after application of myoinositol $(p=0.01$ and $\mathrm{p}=0.01$, respectively) whereas TRPM7 and CACNA1B expression did not change significantly when compared to control (for both) (Figure 4). It decreased TRPM2 expression to 0,27 times, TRPV1 to 0,28 times, TRPM7 to 0,62 times and CACNA1B to 0,91 times.

\section{Discussion}

We analysed the effect of myoinositol on non pregnant rat uterus muscle contraction for the first time and its results indicated that myoinositol causes uterine contractions possibly by permitting the influx of of extracellular calcium to the intracellular area.

Studies investigating the contractility patterns of human uterus was started in 1899 by Heinricius and by the development of intrauterine devices these studies become more abundant (15). After that days, many studies have been done and it is discovered that uterus is not a quiescent organ.

Uterine peristaltic activity changes throughout the menstruel cycle. Contractility increases with the progression of follicular phase (16). After ovulation, contractility of the uterus decreases due to the progesteron which is known to be important for successful implantation (17).

After the observation of these physiological changes, many studies were done and showed that excessive uterine contractions decrease implantation and pregnancy rates and these results proved the importance of uterine quiescence in implantation period (18-20). After the observation of impact of uterine contraction to implantation, the effects of many hormones have been studied.

A study evaluated the differences in uterus contraction which occurs after hCG application and found that contractions nearly stops at the seventh day of hCG administration. They came to the conclusion that success of transfer of day 5 embryo may be due to this effect (21). Celik et al. (22) showed the utero-relaxing effect of estrogen, progesteron and hCG in the myometrium of non pregnant ooferectomized rats.

Also the effects of some commonly used drugs on uterus contraction are studied. It is observed that glibenclamide and metformin, drugs used in diabetes and PCOS, does not change the amplitude and frequency of spontaneous uterine contractions (23). It was found in another rat study that T4 treatment changes myometrial activity (24).

After the observation of increased frequency of uterine contraction during ovarian stimulation cycles compared with the corresponding phase of natural menstruel cycles in a number of studies, a new pharmaterapeutic target arised and investigation of drugs reducing the contractility of uterus increased and conflicting results are found $(25,26)$. Moon and colleagues reported that piroxicam, a nonsteroidal anti-inflammatory drug (NSAID), increased the implantation and pregnancy rate in women undergoing assistedreproductive technology (ART) (27). In contrast, indomethacin which is a different type of NSAID did not improve the implantation rates (28). It is reported that hyoscine is more effective than indomethacin in ART cycles (29). On the other hand, ritodrine did not increase implantation (30).

In the light of above studies it can be concluded that management of silency of uterus in the implantation phase is critically important in

East J Med Volume:23, Number:2, April-June/2018 
patients desiring pregnancy. So we planned to study the effect of myoinositol which is a drug commonly used in infertility clinics. While accumulating evidence suggests that myo-inositol improves the quantity and quality of oocytes in women with PCOS undergoing ART, data on its effects on live birth rates is much more limited.

It is known that smooth muscle contraction is mostly dependent on influx of calcium but release of sarcoplasmic reticulum calcium can also cause contraction. It is known that phosphoinositides play a role in muscle calcium signaling in differentiated muscle by the release of calcium from the sarcoplasmic reticulum. Phaneuf et al. (31) reported that oxytocin causes contraction by the activation of phospholipase $\mathrm{C}$ to produce inositol-1, 4, 5-triphosphate which releases calcium from intracellular stores and stimulates uterine contractions. Lan et al. (32) demonstrated that atosiban significantly decreased the mean frequency of uterine contractions and improved pregnancy rates.

We demonstrated that myoinositol causes contractions in rat uterus muscle. By the use of calcium free solution, it is also demonstrated that myoinositol shows its effect by causing influx of calcium from the extracellular area. It does not cause release of calcium from the sarcoplasmic reticulum as predicted.

To support this finding, TRPV1, TRPM2,TRPM7 and CACNA1B channels are studied. Consistent with our results obtained from the isolated organ bath study, it is observed that expression of mRNA levels of channels, TRPV1 and TRP decreased in statistically significant amounts and mRNA levels of channels located on plasma membrane did not change in statistically significant amount. In our study, we only studied four channels that are permeable to calcium. The study of more calcium channels can show other channels responsible from the influx of calcium. In this sense, our study offers a preliminary data.

Our study is important in many aspects. It is the first study showing the effect of myoinositol on uterus contraction. It is also demonstrated that ion channels on cell membrane are used for the calcium influx. Different channels including TRPs are investigated and it is shown that their levels changed differently after the application of drug.

This study has some limitations. It is an in vitro study done on rat myometrium. And only a few channels are studied.

In conclusion although it is demonstrated in our study that myoinositol caused contraction in uterus of an experimental rat model, further in vivo studies should be designed to show the direct effect of myoinositol on uterus contraction and its possible role in fertilization, implantation and continuation of pregnancy. Since importance of TRP channels in calcium homeostasis of smooth muscle has been started to be understood, they can be targets of drugs regulating uterus contraction in obstetrics and reproductive medicine. We hope that our study might contribute researchers in this aspect.

Conflict of interest: None of the authors have conflicts of interest and financial support is not taken.

\section{References}

1. Legro RS, Finegood D, Dunaif A. A fasting glucose to insulin ratio is a useful measure of insulin sensitivity in women with polycystic ovary syndrome. J Clin Endocrinol Metab 1998; 83(8): 2694-2698.

2. Dinicola S, Chiu TT, Unfer V, Carlomagno G, Bizzarri M. The rationale of the myo-inositol and D-chiro-inositol combined treatment for polycystic ovary syndrome. J Clin Pharmacol 2014; 54(10): 1079-1092.

3. Karen A, Richard AA, Stephen BS. Phosphatidylinositol and inositol phosphate metabolism. Cell Sci 2001; 114(12): 2207-2208.

4. Clements RS Jr, Darnell B. Myo-inositol content of common foods: development of a high-myoinositol diet. Am J Clin Nutr 1980; 33(9): $1954-$ 1967.

5. Maurizio N, Raffaella P. Combined treatment with myo-Inositol and selenium ensures euthyroidism in subclinical hypothyroidism patients with autoimmune thyroiditis. J Thyroid Res 2013; Article ID 424163.

6. Downes CP. The cellular functions of myoinositol. Biochem Soc Trans 1989; 17(2): 259 268.

7. Downes CP, Macphee CH. Myo-inositol metabolites as cellular signals. Eur J Biochem 1990; 193(1): 1-18.

8. Greene ND, Stanier P, Copp AJ. Genetics of human neural tube defects. Hum Mol Genet 2009; 18(R2): R113-129.

9. Bizzarri M, Carlomagno G. Inositol: history of an effective therapy for Polycystic Ovary Syndrome. Eur Rev Med Pharmacol Sci 2014; 18(13): 1896-1903.

10. Colodny L, Hoffman RL. Inositol-clinical applications for exogenous use. Altern Med Rev 1998; 3(6): 432-447. 
11. Nilius B, Owsianik G. The transient receptor potential family of ion channels. Genome Biol 2011; 12(3): 218-220.

12. Oancea E, Vriens J, Brauchi S, Jun J, Splawski I, Clapham DE. TRPM1 forms ion channels associated with melanin content in melanocytes. Sci Signal 2009; 2(70): ra21.

13. Lange I, Yamamoto S, Partida-Sanchez S, Mori Y, Fleig A, Penner R. TRPM2 functions as a lysosomal Ca2+-release channel in beta cells. Sci Signal 2009; 2(71): ra23.

14. Turner H, Fleig A, Stokes A, Kinet JP, Penner R. Discrimination of intracellular calcium store subcompartments using TRPV1 (transient receptor potential channel, vanilloid subfamily member) release channel activity. Biochem J 2003; 371(Pt 2): 341-50.

15. Hendrics $\mathrm{CH}$. A new technique for the study of motility in the non-pregnancy human uterus. J Obstet Gynaecol Br Commonw 1964; 71: 712715.

16. Leyendecker G, Kunz G, Wildt L, Beil D, Deininger $H$. Uterine hyperperistalsis and dysperistalsis as dysfunctions of the mechanism of rapid sperm transport in patients with endometriosis and infertility. Hum Reprod 1996; 11(7): 1542-1551.

17. Cibils LA. Contractility of the nonpregnant human uterus. Obstet Gynecol 1967; 30(3): 441461.

18. Fanchin R, Righini C, Olivennes F, Taylor S, de Ziegler D, Frydman R. Uterine contractions at the time of embryo transfer alter pregnancy rates after in-vitro fertilization. Hum Reprod 1998; 13(7): 1968-1974.

19. Lesny P, Killick SR, Robinson J, Raven G, Maguiness SD. Junctional zone contractions and embryo transfer: is it safe to use a tenaculum? Hum Reprod 1999; 14(9): 2367-2370.

20. Speroff L, Fritz MA. Clinical gynecologic endocrinology and infertility. 8th Edition, Lippincott Williams \& Wilkins, Philadelphia 2011: 1150-1151.

21. Fanchin R, Ayoubi JM, Righini C, Olivennes F, Schönauer LM, Frydman R. Uterine contractility decreases at the time of blastocyst transfers. Hum Reprod 2001; 16(6): 1115-1119.

22. Celik O, Hascalik S, Tagluk ME, Elter K, Parlakpinar $\mathrm{H}$, Acet A. Assessment of myoelectrical signal parameters in estrogen, progesterone, and human chorionic gonadotropin administered in nonpregnant rat myometrium after ovariectomy. Fertil Steril. 2008; 89(1): 188-198.

23. Kelany ME, Alqahtani S, Alkuriji A, Al-Omar S. Role of the antidiabetic drugs: Glibenclamide and metformin on the contractility of isolated rat uteri. Pak J Pharm Sci 2016; 29(1): 51-57.

24. Corriveau S, Blouin S, Raiche E, Nolin MA, Rousseau E, Pasquier JC. Levothyroxine treatment generates an abnormal uterine contractility patterns in an in vitro animal model. Jour of Clinical \& Translational Endoc 2015; 2(4): 144-149.

25. Fanchin R, Ayoubi JM, Olivennes F, Righini C, de Ziegler D, Frydman R. Hormonal influence on the uterine contractility during ovarian stimulation. Hum Reprod 2000: 15(1): 90-100.

26. Lyons EA, Taylor PJ, Zheng XH, Ballard G, Levi CS, Kredentser JV. Characterization of subendometrial myometrial contractions throughout the menstrual cycle in normal fertile women. Fertil Steril 1991; 55(4): 771-774.

27. Moon HS, Park SH, Lee JO, Kim KS, Joo BS. Treatment with piroxicam before embryo transfer increases the pregnancy rate after in vitro fertilization and embryo transfer. Fertil Steril 2004; 82(4): 816-820.

28. Bernabeu R, Roca M, Torres A, Ten J. Indomethacin effect on implantation rates in oocyte recipients. Hum Reprod 2006; 21(2): 364-369.

29. Sohrabvand F, Haghollahi F, Maasomi M, Asgarpoor L, Shariat M, Hamedani M. The effect of administrating indomethacin or hyoscine before embryo transfer on ART outcome (a pilot study). Iran J Reprod Med 2009; 7: 169-173.

30. Rabiee S, Farimani M, Ahmadi M. Evaluation of the effect of oral ritodrine on implantation rate in in-vitro fertilization-embryo transfer cycles. Iran J Reprod Med 2011; 9(3): 239-242.

31. Phaneuf S, Europe-Finner GN, Carrasco MP, Hamilton CH, López Bernal A. Oxytocin signalling in human myometrium. Adv Exp Med Biol 1995; 395: 453-467.

32. Lan VT, Khang VN, Nhu GH, Tuong HM. Atosiban improves implantation and pregnancy rates in patients with repeated implantation failure. Reprod Biomed Online 2012; 25(3): 254 260. 